\title{
Hydrological Consequences of Global Warming
}

Norman Miller, Climate Science Department, Lawrence Berkeley National Laboratory, and the Geography Department, University of California, Berkeley.

Key words: accelerated hydrologic cycle, early snowmelt, sea level rise, droughts, floods

\begin{abstract}
The 2007 Intergovernmental Panel for Climate Change indicates there is strong evidence that the atmospheric concentration of carbon dioxide far exceeds the natural range over the last 650,000 years, and this recent warming of the climate system is unequivocal, resulting in more frequent extreme precipitation events, earlier snowmelt runoff, increased winter flood likelihoods, increased and widespread melting of snow and ice, longer and more widespread droughts, and rising sea level. The effects of recent warming has been well documented and climate model projections indicate a range of hydrological impacts with likely to very likely probabilities (67 to 99 percent) of occurring with significant to severe consequences in response to a warmer lower atmosphere with an accelerating hydrologic cycle.
\end{abstract}

The hydrologic cycle, which includes water fluxes and stores in the atmosphere, oceans, and land regions, is accelerating due to global warming. Figure 1 schematically shows the primary hydrologic cycle compartments and fluxes (Trenberth et al. 2007). The total volume of water in the Earth system is approximately $1.36 \times 10^{9}$ cubic kilometers, with oceans storing over 97 percent of all the water on our planet, 2.9 percent is stored as freshwater in lakes, rivers, ice, snow, and available groundwater, and approximately 0.1 percent is in the atmosphere. The cycling of water consists of atmospheric water vapor transport and precipitation, surface evaporation, transpiration from vegetation, infiltration of water into the ground, overland runoff and riverflow, and water stored in the oceans, snow, glaciers, permafrost, and deep groundwater. Surface water evaporates and is transported by the winds and precipitates back to the surface, where a portion is reevaporated into the atmosphere, another portion infiltrates into the ground, and the remainder runs off into rivers and ultimately into the oceans.

At present, approximately $413 \times 10^{3}$ cubic kilometers per year of water is evaporated from the oceans and about $73 \times 10^{3}$ cubic kilometers per year evaporates and transpires from land surfaces. The atmosphere annually returns $373 \times 10^{3}$ cubic kilometers of precipitation to the oceans and $113 \times 10^{3}$ cubic kilometers of precipitation to land. These processes operate at different rates for different locations, depending on the temperature of the lower atmosphere (troposphere) and land and ocean surfaces, as well as the wind speed and direction, and amount of radiative heating. The atmosphere has the shortest residence time ranging from seconds to weeks, and is characterized by clouds, storms, 
and other weather processes. Conversely, the oceans, glaciers, and deep groundwater have much longer residence times, ranging from months to millennia.

The hydrologic cycle is directly linked to the amount of atmospheric absorption, reflection, and transmission of the sun's incoming energy (short wave radiation), as well as the amount of long wave radiation emitted from the land and ocean surfaces. Naturally occurring gases have helped to regulate the atmospheric radiation balance and resulting temperature. However, the increasing rate of human-based emissions of carbon dioxide and other heat absorbing gasses (e.g. methane) has changed this balance, leading to an unprecedented warming of the lower atmosphere. The 2007 Intergovernmental Panel for Climate Change (IPCC 2007) indicates there is strong evidence that the atmospheric concentration of carbon dioxide far exceeds the natural range over the last 650,000 years, and this recent warming of the climate system is unequivocal, resulting in more frequent extreme precipitation events, earlier snowmelt runoff, increased winter flood likelihoods, increased and widespread melting of snow and ice, longer and more widespread droughts, and rising sea level. The effects of recent warming has been well documented and climate model projections indicate a range of hydrological impacts with likely to very likely probabilities (67 to 99 percent) of occurring with significant to severe consequences in response to a warmer lower atmosphere with an accelerating hydrologic cycle.

As the troposphere continues to warm an additional $1-6^{\circ} \mathrm{C}$ during this century, the acceleration of the hydrologic cycle will be more evident. One of the most sensitive hydrologic components is the change in atmospheric water vapor and the resulting changes in the distribution, type, and timing of precipitation. Warmer air mass has the ability to hold more water vapor, resulting in more extreme precipitation events in the form of more frequent flooding and more extensive and longer lasting droughts. This change in water vapor and precipitation roughly translates into dry regions very likely to become drier and wet regions very likely to become wetter. Figure $2 \mathrm{a}$ depicts these trends for a doubling of the 1990 atmospheric concentration of carbon dioxide, where the endof-the-century precipitation increases at mid-to-high latitudes, and semi-arid regions dry and extend northward. The stippled regions are where more than 90 percent of the IPCC climate model projections agree. Soil moisture is almost certain to decrease as evaporation increases globally with the planet heating up (Figure $2 b$ and c). Runoff is very likely to increase at high latitudes with increasing precipitation and to decrease at mid-latitudes with decreasing precipitation and increasing evapotranspiration.

High latitude precipitation increases will result in increased surface runoff and freshwater inflow to northern oceans, causing a decrease in the salinity, suggesting a slow down of the Atlantic Ocean thermohaline circulation of warm tropical water northward and deep cold polar water southward. If global warming continues unabated, such a slow down may tip beyond a stability threshold resulting in a shutdown of this ocean circulation and a long-term shift in climate patterns in Europe.

Global warming is causing earlier seasonal melting of Alpine snowpack, shifting the timing of snowmelt runoff worldwide. Glacial surveys of equatorial and mid-latitude glaciers show retreat of up to 50 percent in the last 25 years and evidence is very strong 
that equatorial glaciers will completely disappear by about 2030. Many regions that rely on snowmelt for domestic and industrial water resources are beginning to feel the effects of this change. Equatorial glaciers have been retreating at such a fast rate that they are expected to vanish completely within about 20 years. Alpine snow reduction is and will further impact water resources supply and demand, including fresh water for domestic uses, agricultural and other industrial uses, and recreation. An increase in winter and early spring floods are forecast for the future, along with a significant decrease in late spring and summer runoff.

Many emerging and undeveloped nations will be impacted by decreasing freshwater availability as dry regions expand and drought becomes a more frequent phenomena. Africa and Southeast Asia are some of the most susceptible regions to drought and are likely to have an increase in famines, water wars, and population declines. Reduced snowpack and early melt will dramatically shift available water resources for several river systems flowing out of the Himalayas, impacting Southeast Asia. A combined consequence is the effect on water quality and its impact on human and animal health. Cultures may likely shift with mass migrations in response to agriculture failures as a result of freshwater loss.

Alpine glaciers and snowpack provide freshwater to a large segment of society, especially the western U.S. The western U.S. is one of the most susceptible regions to drying and water managers are developing adaptation and coping strategies for less available water. Western U.S. snowpack has been melting earlier in the spring, the total volume of snowmelt runoff in rivers has been occurring earlier, and summer flows have been below average. These trends are being observed worldwide and major rivers with snowmelt runoff, such as the Colorado River, Ganges River, MacKenzie River, Rhine River, Rio Grande River, Yangtze River, and the Yukon River will all be subject to reduced flows and reduced hydroelectric power production due to global warming.

Ski resorts in the Alps have been putting down protective covers to slow the retreat of glacial snow in the hope of extending the future of this industry. The sensitivity of reduced runoff is dependent upon the elevation of the snowline and the amount of snow cover area. Regions with most of the snow cover area close to freezing, such as the Cascade Mountains and the Sierra Nevada Mountains will be the first to experience significant reductions as temperatures continue to rise. The California Climate Change Assessment (2006) has put upper and lower snowpack reduction bounds of 90 and 60 percent loss, respectively, putting significant pressure on water resource managers to design new coping strategies with an increased reliance on groundwater storage for increasing water demand in California. Groundwater storage is expected to become more important in a warmer world, but a need for deeper wells and increased electricity costs to extract groundwater will result due to groundwater overdraft.

Other hydrologic components of the climate system that are changing include Arctic Sea ice decrease, loss of ice from the West Antarctic Ice Shelf, glacial loss from Antarctic and Greenland land mass, and melting of permafrost resulting in sinking land that damages infrastructure and the release of methane into the atmosphere. The recent 
calving of glaciers from the West Antarctic Ice Shelf does not increase sea level, because ice shelves do not displace water. However, the land-based ice is undermined from below and can result in a destabilization and ice flow from inland to the sea with major sea level changes. The most significant abrupt hydrologic change is the melting or release of Greenland and or Antarctic glacial ice that results in sea level increases of five or more meters. Such a scenario would drastically change many coastal regions to with large population disruptions (e.g. Florida, Bangladesh, Island Nations).

The Global Earth Observing System of Systems (GEOSS) is United Nations activity for monitoring climate change, including the hydrologic cycle, and will lead to improved disaster prevention and management. GEOSS includes satellite remote sensed observations, surface observations, and airborne observations.

There is very high confidence that these hydrologic changes are happening, are manmade, and will last for centuries due to the slow response time of the oceans. Society will need to advance coping and adaptation strategies for our warming planet.

\section{Acknowledgment:}

This work was supported by the U.S. Department of Energy under Contract No. DEAC02-05CH11231. 


\section{References:}

California Climate Change Assessment, 2006: Our Changing Climate, Assessing the Risks to California. http://www.energy.ca.gov/2006publications/CEC-500-2006077/CEC-500-2006-077.PDF

Intergovernmental Panel on Climate Change, Fourth Assessment Report, 2007: Climate Change 2007. http://www.ipcc.ch

Trenberth, K.E., L. Smith, T. Qian, A, Dai, and J. Fasullo, 2007: Estimates of the global water budget and its annual cycle using observational and model data. Journal of Hydrometeorology, 8, 758-769. 


\section{Hydrological Cycle}

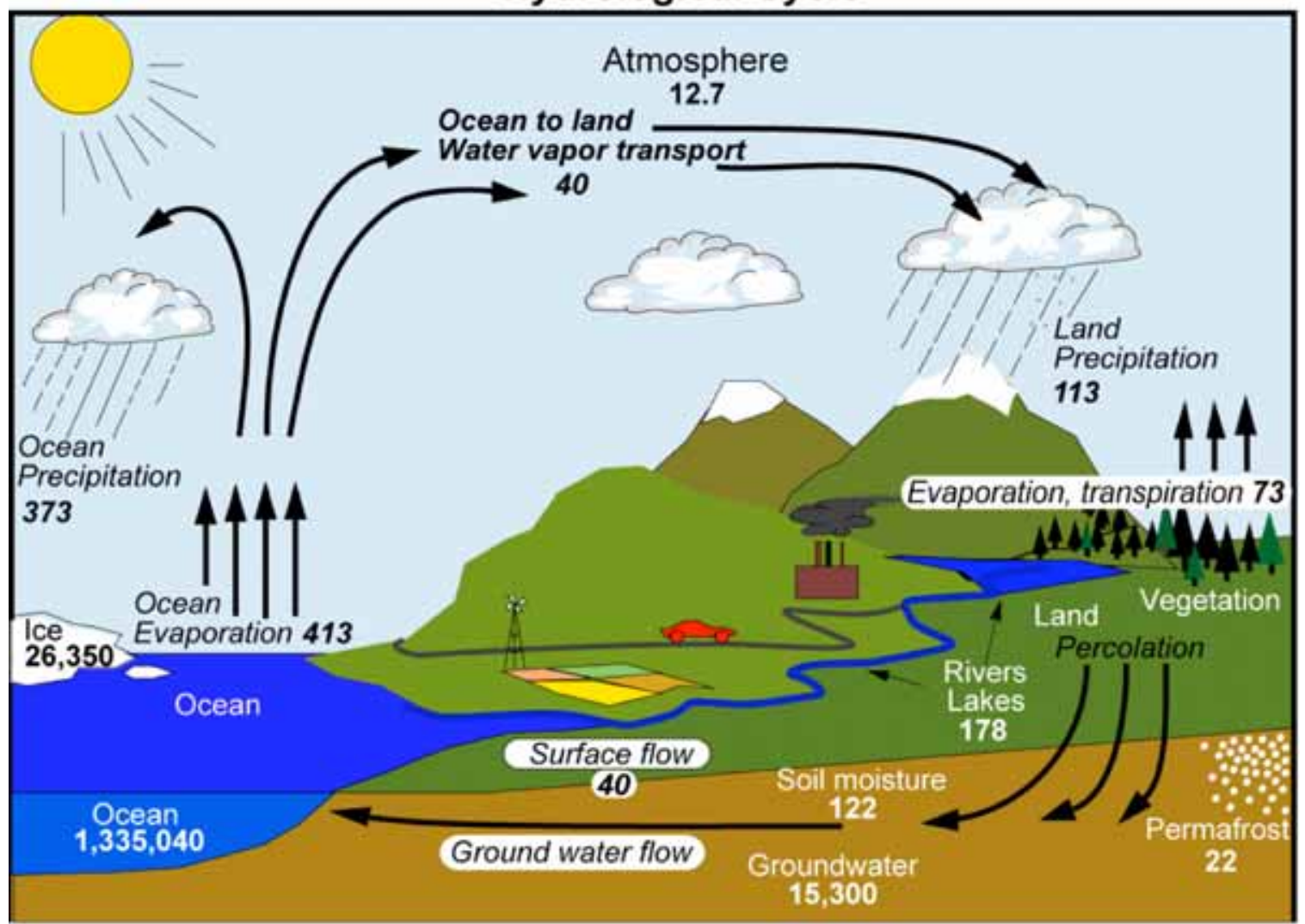

Units: Thousand cubic $\mathrm{km}$ for storage, and thousand cubic $\mathrm{km} / \mathrm{yr}$ for exchanges

Figure 1. The hydrologic cycle is characterized by evaporation and transpiration from the surfaces, transport of water vapor in the atmosphere by the wind, clouds and precipitation, and water storage in snow, glaciers, groundwater, and oceans. (Trenberth et al. 2006) 
a) Precipitation
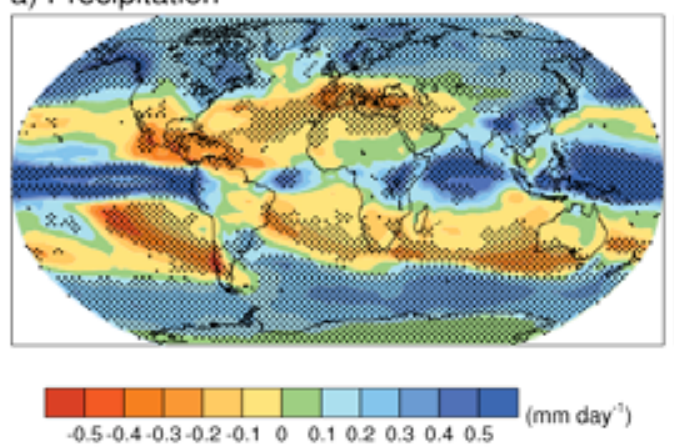

c) Runoff
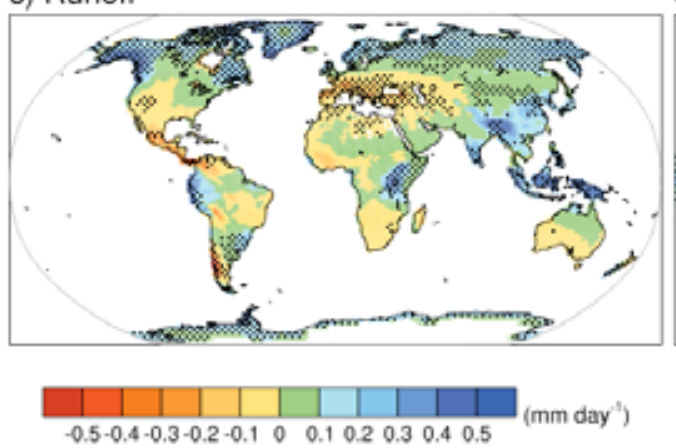

b) Soil moisture
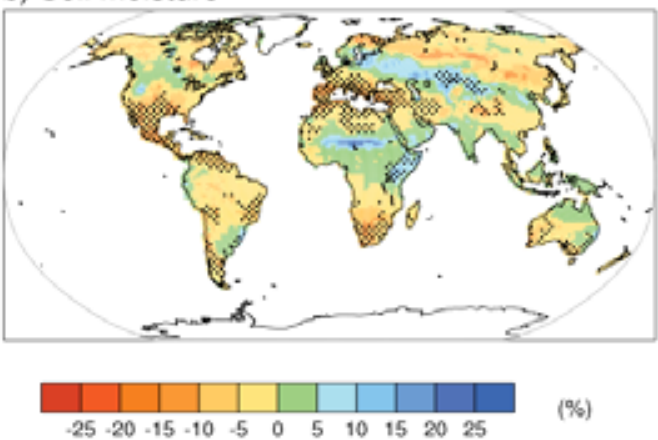

(\%)

d) Evaporation

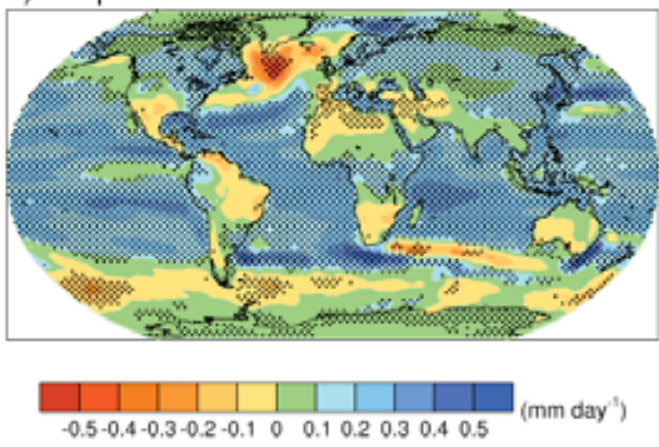

Figure 2. Spatial patterns of climate model projections of (a) precipitation, (b) soil moisture, (c) runoff, and (d) evaporation for 2090-2099 under the mid-range A1B emission scenario from the Intergovernmental Panel for Climate Change 2007 